\title{
Study on the Role of Colonoscopic Biopsy in Rectal Bleeding Patients with Ulcerated Hyperemic Mucosa only
}

\author{
Dalia M Badary ${ }^{1 *}$, Ahmed Ashmawy ${ }^{2}$ and Adnan Ahmed Mohamed ${ }^{3}$ \\ ${ }^{1}$ Department of Pathology, Assiut University, Egypt \\ ${ }^{2}$ Department of Internal Medicine, Assiut University, Egypt \\ ${ }^{3}$ Department Tropical medicine and gastroenterology, Assiut University, Egypt
}

Submission: September 14, 2018; Published: October 05, 2018

"Corresponding author: Dalia M Badary, Lecture of pathology, Department of Pathology, Assuit University, Al-Gamaa street, Assiut, Egypt, Tel: 00201066189050; Email: hamasat82@yahoo.com

Abstract

Colonoscopy is the examination of choice for diagnosis and treatment of patients complaining of rectal bleeding. As number of cases with colonoscopy shows only ulcerated hyperemic mucosa is not low, we have performed this study in order to determine the role of colonoscopy in determining the cause of bleeding per rectum in those patients by histopathological evaluation of their biopsies.

Methods: This research included 500 adult patients presented by bleeding per rectum referred to Assiut university hospital (considered the largest center of upper Egypt, receiving cases from all hospitals of upper Egypt) covering the period from 2014 to 2017. All patients were subjected to fibre-optic colonoscopy after necessary preparation and their colonoscopy revealed ulcerated hyperemic mucosa only. Biopsies from these ulcerated hyperemic mucosae taken and diagnosis was based on histopathologic findings

Results: Of the 500 patients enrolled, non-specific in $40(8 \%)$ patients, while the most common pathological finding was solitary rectal ulcer in $200(40 \%)$ followed by ulcerative colitis in $100(20 \%)$, eosinophilic proctitis in $55(11 \%)$, infectious colitis in 40 (8\%), indeterminate colitis in $25(5 \%)$, bilharzial proctitis in $20(4 \%)$, hemorrhoids in $10(2 \%)$, ischemic colitis in $5(1 \%)$ patients and colonic adenocarcinoma in $5(1 \%)$

Conclusion: We conclude that Colonoscopy considered the most cost-effective tool for diagnosis and management of colorectal disorders. Inflammatory and ulcerative colorectal lesions are the most common causes of bleeding per rectum in colonoscopy with no masses. Colorectal carcinoma may be diagnosed early by colonoscopy before forming mass.

Keywords: Colonoscopy; Bleeding per rectum; Colitis; Ulcer; Bilharziasis

\section{Introduction}

The gastrointestinal (GI) tract is a highly vascularized organ thus any pathology affecting its mucosa and vasculature can lead to GI bleeding [1]. GI bleeding is an alarming sign for presence of pathology in any age group and must be approached meticulously. Bleeding per rectum which means bleeding from a site distal to ligament of Treitz is considered most common cause of lower GI bleeding [2].

There are several etiologies for rectal bleeding and a complete evaluation and early diagnosis is very important. Bleeding per rectum ranging from mild conditions requiring little or no treatment to severe and life-threatening ones requiring immediate intervention according to the etiologies [3]. The etiologies include hemorrhoids, anal fissures, solitary rectal ulcer, inflammatory bowel disease (IBD), diverticulosis, proctitis, ischemic colitis, infectious colitis, colonic polyps and cancer colon.
Proctosigmoidoscopy followed by colonoscopy is the examination of choice for diagnosis and treatment of patients complaining of rectal bleeding [4]. As number of cases with colonoscopy shows only ulcerated hyperemic mucosa is not low, we have performed this study in order to determine the role of colonoscopy in determining the cause of bleeding per rectum in those patients by histopathological evaluation of their biopsies.

\section{Materials and Methods}

This research included 500 adult patients presented by bleeding per rectum referred to Assiut university hospital (considered the largest center of upper Egypt, receiving cases from all hospitals of upper Egypt) covering the period in three years from 2014 to 2017. All patients were subjected to fibre-optic colonoscopy after necessary preparation and their colonoscopy revealed ulcerated hyperemic mucosa only. Biopsies from these 
ulcerated hyperemic mucosae taken and diagnosis was based on histopathologic findings. The inclusion criteria were rectal bleeding with ulcerated hyperemic mucosa only at colonoscopy. The study parameters included age sex and histopathological findings. The histopathological diagnosis based on the classification of Atlas of Non-tumor Pathology - Gastrointestinal Diseases [5].

The biopsy samples have been analyzed in detail under light microscope using hematoxylin- Eosin stain. The collected data were submitted to descriptive statistical analysis.

Results

A total of 500 patients (300 males and 200 females) with mean age 40 years. The presenting symptoms were hematochezia in 300 (60\%), bloody diarrhea in 190 (38\%), and positive occult blood test in $10(2 \%)$ patients. The most common accompanying symptom was abdominal pain in $300(60 \%)$ patients followed by fever in 100 (20\%), weight loss in 80 (16\%), and iron deficiency anemia in $20(4 \%)$ patients.

Biopsy samples were non-specific in 40 (8\%) patients, while the most common pathological finding was solitary rectal ulcer in 200 (40\%) followed by ulcerative colitis in 100 (20\%), eosinophilic proctitis in 55 (11\%), infectious colitis in 40 (8\%), indeterminate colitis in 25 (5\%), bilharzial proctitis in $20(4 \%)$, hemorrhoids in $10(2 \%)$, ischemic colitis in 5(1\%) patients and colonic adenocarcinoma in 5 (1\%) (Figure 1).

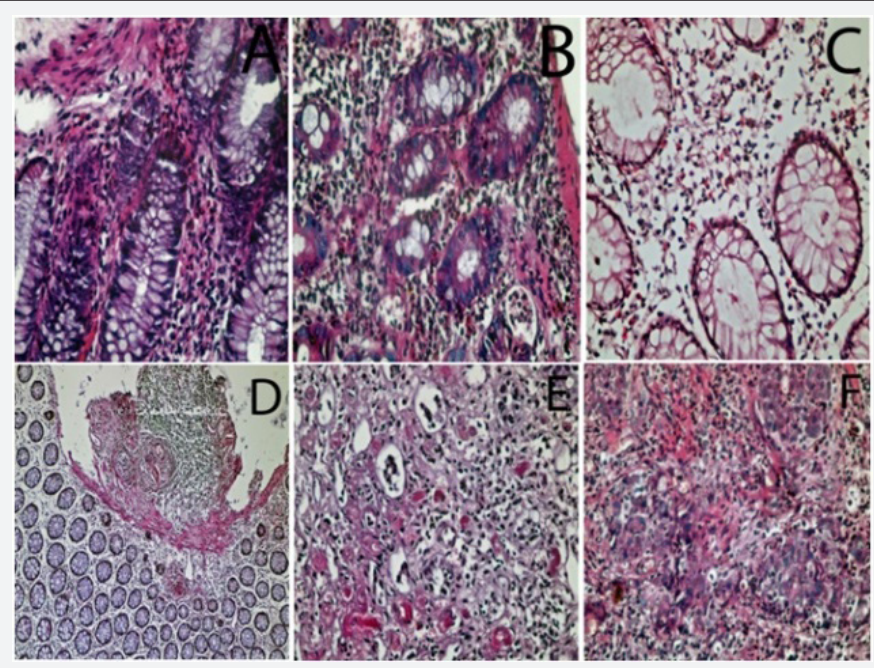

Figure 1: A) Solitary rectal ulcer. muscularis mucosa fibers splay between the glands; H\&E staining (x400). B) Ulcerative colitis. Crypt abscesses and mucin depletion; H\&E staining (x400). C) Esinophilic proctitis: excessive esinophils at lamina propria; H\&E staining ( $x 400)$. D) Bilharzial colitis: Multiple ova in the submucosa; H\&E staining (x200). E) Ischemic colitis: multiple thrombi at blood vessels in lamina propria with degenerated glands; $\mathrm{H} \& \mathrm{E}$ staining $(x 400)$. F) Colonic adenocarcinoma: malignant glands infiltrate the submucosa; $\mathrm{H} \& \mathrm{E}$ staining (x400).

\section{Discussion}

The colon is the main target of several functional and pathological disorders, which have an acute or chronic presentation. Colonoscopy is a main effective method for surveillance of colonic lesions. Several studies were done to evaluate the role of colonoscopy in diagnosis and management of gastrointestinal disorders [6,7].

Our study involved 500 patients, whose colonoscopy revealed ulcerated hyperemic mucosa only to determine the role of colonoscopy in determining the cause of bleeding per rectum in those patients by histopathological evaluation of their biopsies.

Solitary rectal ulcer represents the most common cause of rectal bleeding in our study $40 \%$ of cases which is nearly similar to [8]. Ulcerative colitis represented $20 \%$ of cases and indeterminate colitis represented $5 \%$ of cases with which is similar to the finding by some authors $[6,9]$.

Nonspecific colitis was the endoscopic findings in 40 cases only which represented $8 \%$ of all cases which appear to be very low in relation to specific pathology in 460 cases which is similar to many studies $[10,11]$. This makes colonoscopy in those patients with a great value.

Colonoscopic finding in 5 cases (1\%) were diagnosed as cancer colon was hyperemic ulcerative mucosa only revealed the importance of biopsy in those patients. Eosinophilic proctitis and infectious colitis represent also 55 (11\%) and 40 (8\%) respectively which is considered is not low in relation to other studies [12]. While hemorrhoids and ischemic colitis represent only $2 \%$ and $1 \%$ respectively, but this considered high in relation to other studies [8].

Bilharzial colitis was found in 20 cases ( $46 \%$ of all cases of the study) which is nearly similar to many authors $[10,13,14]$ while Thakeb et al., [15] in 1987 found bilharziasis in $68.7 \%$. The difference reflects the advanced management of bilharziasis in Egypt in the last three decades.

\section{Conclusion}

Colonoscopy considered the most cost-effective tool for diagnosis and management of colorectal disorders. Inflammatory and ulcerative colorectal lesions are the most common causes of 
bleeding per rectum in colonoscopy with no masses. Colorectal carcinoma may be diagnosed early by colonoscopy before forming mass (with ulcerative hyperemic mucosa only).

\section{Competing Interest}

The authors declare that they have no competing interests.

\section{Funding}

The authors received no financial or other support for the research reported in this manuscript.

\section{References}

1. Dar IA, Waseem Raja Dar, Mushtaq Ahmad Khan, Basharat Ahmad Kasana, Najeeb Ullah Sofi, et al. (2015) Etiology, clinical presentation, diagnosis and management of lower gastrointestinal bleed in a Tertiary Care Hospital in India: A retro-prospective study. Journal of Digestive Endoscopy 6(3): 101-109.

2. Gimiga N, Burlea Marin, Diaconescu Smaranda, Olaru Claudia (2015) An assessment of the causes of lower gastrointestinal bleeding in a children's hospital in northeastern Romania. Archives of Biological Sciences 67(2): 715-720.

3. Picardo NG, NA Ajayi, IA Ajayi (2017) Lower gastrointestinal endoscopy in Enugu, Nigeria: an experience with 151 cases. Nigerian Journal of Gastroenterology and Hepatology 9(1): 15-20.

4. Zia N, Hussain T, Salamat A, Mirza S, Hassan F, et al. (2008) Diagnostic evaluation of patients presenting with bleeding per rectum by colonoscopy. J Ayub Med Coll Abbottabad 20(1): 73-76.

5. Fenoglio-Oreiser C (1989) Non-neoplastic diseases of esophagus. Gastrointestinal pathology an atlas and text. p. 35-37.

6. Younis HA, HM Moustafa, MS Alaam (2003) Value of colonoscopy in the diagnosis of lower gastrointestinal disorders. AAMJ 1(3).
7. Sodhi JS, Ajaz Ahmed, Abid Shoukat, Bashir Ahmed Khan, Gul Javid, et al. (2013) Diagnostic role of capsule endoscopy in patients of obscure gastrointestinal bleeding after negative CT enterography. Journal of Digestive Endoscopy 4(4): 107.

8. Zahmatkeshan M, Fallahzadeh E, Najib K, Geramizadeh B, Haghighat M, et al. (2012) Etiology of Lower Gastrointestinal Bleeding in Children: A Single Center Experience from Southern Iran. Middle East Journal of Digestive Diseases 4(4): 216-223.

9. Price AB (1978) Overlap in the spectrum of non-specific inflammatory bowel disease--'colitis indeterminate'. Journal of clinical pathology 31(6): 567-577.

10. Shah H, T Manohar (2016) Clinical Endoscopic Parameters of Upper Gastrointestinal Bleeding. Int J Com Health and Med Res 2(1): 8-13.

11. Badiger RH, Santosh Hajare, Ravindra Kantamaneni, Ashray Kole, Deebanshu (2017) Etiological profile of patients presenting with lower gastrointestinal bleeding at tertiary care hospital at Belagavi: a cross sectional study. International Journal of Advances in Medicine 4(5): 1429-1433.

12. Alruzug I, Thamer A. Aldarsouny, Toufic Semaan, Adnan AlMustafa (2016) Lower gastrointestinal bleeding in Saudi patients: a retrospective longitudinal study. J Gastrointest Dig Syst 6(4): 2.

13. Raymond JM, Tissot B, Dartigues JF, Capdenat Saint-Martin E, Vergier JF, et al. (1994) Quality Assessment of Colonoscopy in Usual Practice in a French Area-Aquitaine. Gastroenterol Clin Biol 18(4): 310-316.

14. Khandelwal C (2003) Lower gastrointestinal bleeding. Indian J Surg 65(2): 151-155.

15. Thakeb F, Zakaria S, Miland M (1987) A review of 10 years' experience with colonoscopy. In: Zakaria S, Thakeb F, (Eds,) gastrointestinal Endoscopy; An Egyptian View, (1 $1^{\text {st }}$ edn), National libarary Legal Deposit, p. 83-95.
This work is licensed under Creative Commons Attribution 4.0 License DOI: 10.19080/ARGH.2018.11.555805

\begin{tabular}{|l|}
\hline \multicolumn{1}{|c|}{ Your next submission with JuniperPublishers } \\
will reach you the below assets \\
- Quality Editorial service \\
- Swift Peer Review \\
- Reprints availability \\
- E-prints Service \\
- Manuscript Podcast for convenient understanding \\
- Global attainment for your research \\
- Manuscript accessibility in different formats \\
( Pdf, E-pub, Full Text, audio) \\
- Unceasing customer service \\
Track the below URL for one-step submission \\
https://juniperpublishers.com/online-submission.php \\
\hline
\end{tabular}

